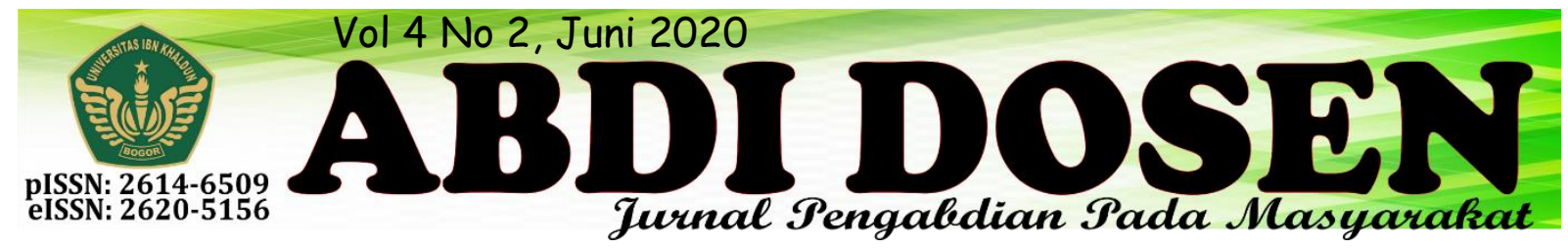

\title{
PENGEMBANGAN KAMPUNG RAMAH LINGKUNGAN DWIKORA MELALUI PERBAIKAN KEADMINISTRASIAN, GREEN AND CLEAN, PENDIDIKAN DAN PEMBERDAYAAN WARGA
}

\author{
Gatot Eka Pramono ${ }^{1}$, Enni Erawati Saragih ${ }^{2}$, Abdul Septiawan $^{3}$ \\ gatot@ft.uika-bogor.ac.id ${ }^{1}$ \\ enni.saragih@gmail.com ${ }^{2}$ \\ abdulseptiawan060813@gmail.com ${ }^{3}$
}

Fakultas Teknik Universitas Ibn Khaldun ${ }^{1}$, Fakultas Ilmu Pendidikan Universitas Ibn Khaldun ${ }^{2}$, Mahasiswa

KKN Kelompok 61\&62 Tahun $2019^{3}$

\begin{abstract}
ABSTRAK
Kampung ramah lingkungan (KRL) merupakan program pemerintah Kabupaten Bogor untuk memelihara lingkungan yang kumuh dan kotor menjadi bersih. Desa Cigudeg merupakan salah satu desa yang menjadi bagian dari percontohan KRL yang diterapkan di Kampung Cicere dan diberi nama Dwikora. Namun program KRL ini masih belum berjalan dengan baik karena masih kurangnya kesadaran warga untuk memilah dan menabung sampah, warga yang masih membakar sampah, program KRL yang masih belum berjalan dengan baik, keadministrasian yang belum rapi, belum adanya pengelolaan sampah organik dan plastik sehingga perlu di dorong dan diperbaiki agar dapat terasa kebermanfaatannya. Tujuan program KKN kelompok 61-62 ini adalah mengembangkan dan memajukan KRL Dwikora agar dapat dirasakan manfaatnya melalui perbaikan keadministrasian, peningkatan kepedulian, pendidikan, pemberdayaan, pendidikan, pengelolaan sampah, penghijauan dan kebersihan.
\end{abstract}

Kata Kunci : Green and Clean, Kampung Ramah Lingkungan, Lingkungan, Pemberdayaan Warga, dan Pendidikan

\section{PENDAHULUAN}

KKN atau Kuliah Kerja Nyata adalah salah satu bentuk kegiatan pengabdian kepada masyarakat oleh Perguruan Tinggi yang dilakukan oleh mahasiswanya di bawah bimbingan dosen dan pimpinan pemerintah daerah. Tujuan KKN dilakukan agar sarjana yang dihasilkan Pergurruan Tinggi mampu menghayati dan menanggulangi masalah-masalah yang muncul dimasyarakat yang umumnya sangat kompleks. Kelompok KKN 61 dan 62 ditempatkan di Desa Cigudeg, Desa Cigudeg ini merupakan salah satu desa dari
16 desa di kecamatan Cigudeg yang berada di barat kabupaten Bogor. Desa cigudeg memiliki beberapa kampung, salah satunya kampung Cicere yang saat ini baru saja menjadi kampung percontohan untuk program pemerintah kabupaten Bogor

Kampung Cicere menjadi kampung percontohan sebagai Kampung Ramah Lingkungan (KRL) yang bernama Dwikora. Kampung ramah lingkungan adalah sebuah program pemeliharaan lingkungan yang dilakukan oleh pemerintah kabupaten Bogor yang tadinya 
kumuh dan kotor menjadi daerah yang bersih dan hijau. Program KRL ini baru saja berjalan kurang lebih setengah tahun lamanya semenjak pembentukkan dan pengesahan pengurus.

Di usianya yang baru berjalan ini, KRL Dwikora Belum berjalan dengan baik. Program KRL ini merupakan program yang membutuhkan perhatian serius baik oleh pemerintah daerah dan masyarakat didalamnya, dimana program KRL yaitu merubah kebiasaan yang kurang baik dari warga yaitu membuang sampah sembarangan menjadi mengumpulkan sampah dan menabungnya di bank sampah., namun kenyataanya, merubah kebiasaan warga dalam satu lingkup Kampung tidaklah mudah, Perlu program-program tepat sasaran yang dapat merubah pola pikir masyarakat sehingga dapat memahami manfaat menjaga lingkungan.

\section{Permasalahan yang dihadapi}

Berdasarkan hasil observasi, ada beberapa permasalahan yang terdapat didesa Cigudeg khususnya Kampung Cicere, diantaranya :

1. Kurangnya kesadaran terhadap kebersihan dan partisipasi warga terhadap bank sampah.

2. Sampah plastik dan organik yang masih dibakar.

3. Belum berjalan secara efektif program kerja Kampung Ramah Lingkungan (KRL) Dwikora.

4. Kurangnya pengelolaan sampah plastik dan organik.

\section{Solusi yang ditawarkan}

Setelah memahami permasalahan hasil observasi di Desa Cigudeg kampung Cicere, kami menawarkan beberapa solusi diantaranya :

1. Edukasi dan penyediaan alat biopori sebagai tempat pembuangan sampah organik.

2. Edukasi dan Penyediaan alat pengolah sampah plastik menjadi paving blok dan batako.

3. Edukasi dan perbaikan tatacara pencatatan buku nasabah dan buku besar bank sampah.

4. Edukasi pentingnya menabung sampah dan menjaga lingkungan dengan pendekatan door to door.

5. Adanya program bimbingan belajar dan bimbingan agama.

6. Pemberdayaan warga mengenai pengelolaan sampah.

7. Adanya program penyuluhan kesehatan perilaku hidup bersih dan sehat kepada anak-anak dan cek kesehatan gratis untuk warga.

8. Pengembangan usaha warga yang menjadi binaan kampung ramah lingkungan.

9. Penataan dan pemanfaatan lahan kosong di lingkungan kampung Cicere.

10. Pengadaan lomba pendidikan umum dan agama.

11. Penyediaan bibit tanaman hias dan obat sebagai penghijauan lingkungan dan tanaman obat warga. 


\section{METODE PENGABDIAN}

Tahapan pelaksanaan untuk kegiatan ini sebagaimana terlihat pada bagan, sebagai berikut :

\section{Tahap Pelaksanaan}

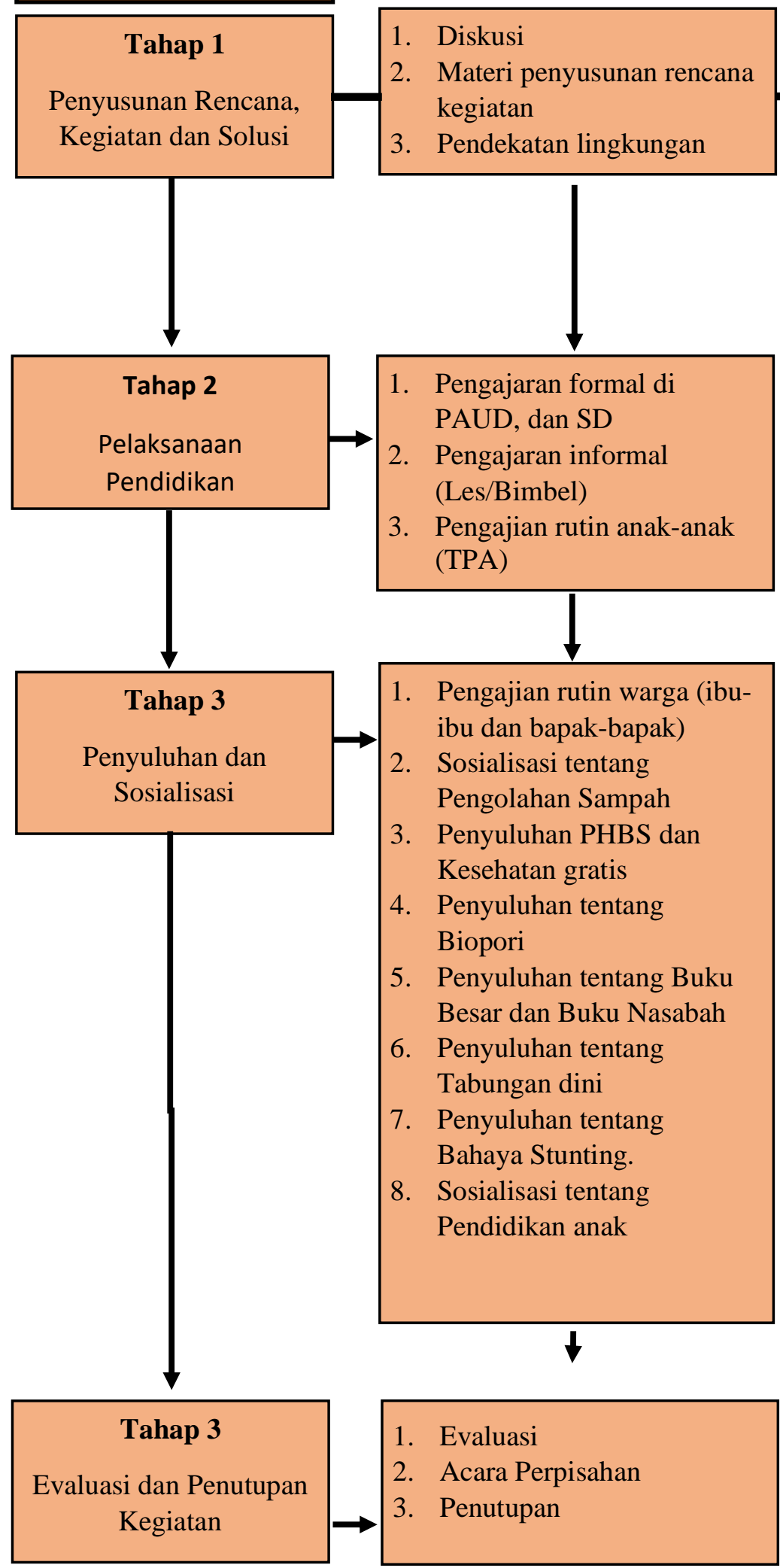

Hal yang Diharapkan

1. Metode formal dan informal bagi Masyarakat

2. Rancangan kegiatan KKN

3. Peningkatan kesadaran masyarakat tentang Pendidikan, Ekonomi, Kesehatan, Agama, dan Teknis di Desa

1. Peningkatan pemahaman pembelajaran siswa

2. Meningtnya keterkaitan siswa untuk belajar

3. Peningkatan membaca dan menulis Al-Quran

1. Pengikat tali silaturahmi masyarakat

2. Meningkatnya kesadaran warga dalam pengolahan sampah

3. Meningkatkan kesadaran masyarakat tentang pentingnya hidup sehat dan pentingnya menjaga kesehatan

4. Dapat mengurangi resiko air menggenang/banjir saat hujan

5. Peningkatan pemahaman warga

6. Meningkatnya kesadaran untuk menanbung sejak dini

7. Meningkatkan kesadaran orangtua tentang gizi anak

8. Meningkatkan ksadaran untuk pendidikan anak.

\section{$\downarrow$}

1. Mengemukakan kendala yang dihadapi dari setiap program kerja

2. Perpisahan bersama Anggota Desa, Warga, dan Pemuda

3. Penutupan kelompok pelaksana KKN 
Jadwal Kegiatan

\begin{tabular}{|c|c|c|c|c|c|}
\hline \multirow{2}{*}{ NO } & \multirow{2}{*}{ KEGIATAN } & \multicolumn{4}{|c|}{ MINGGU } \\
\hline & & 1 & 2 & 3 & 4 \\
\hline & Penyusunan rencana kegiatan & & & & \\
\hline & $\begin{array}{l}\text { Perkenalan dan Sosialisasi kepada masyarakat } \\
\text { tentang rencana kegiatan }\end{array}$ & & & & \\
\hline & Pengajian warga & & & & \\
\hline & Pengajian anak-anak / TPA & & & & \\
\hline & $\begin{array}{l}\text { Mengajar Formal di SDN Cigudeg } 03 \text { dan PAUD } \\
\text { Hamidah }\end{array}$ & & & & \\
\hline & Mengajar Informal / Bimbel MTK dan B.Inggris & & & & \\
\hline & Panitia serta penjurian 17an Kp.Cigudeg RW 20 & & & & \\
\hline & Penyuluhan Stunting & & & & \\
\hline & Penyuluhan PHBS & & & & \\
\hline & Penyuluhan Kesehatan Gratis & & & & \\
\hline & Kegiatan Senam Ibu-Ibu & & & & \\
\hline & Pengembangan usaha rumahan & & & & \\
\hline & Pengolahan limbah kayu & & & & \\
\hline & Tabungan dini & & & & \\
\hline & Penyuluhan buku besar dan buku nasabah & & & & \\
\hline & Biopori & & & & \\
\hline & Renovasi PAUD Hamidah & & & & \\
\hline & Pengecatan Jalan & & & & \\
\hline & Kegiatan Pemungutan sampah untuk KRL & & & & \\
\hline & Pembuatan Sulam Pita (Dibimbing oleh DPL) & & & & \\
\hline & $\begin{array}{l}\text { Festival anak soleh dan lomba cerdas cermat Bahasa } \\
\text { Inggris }\end{array}$ & & & & \\
\hline & Penyerahan Al-Qur'an kepada pihak Pesantren & & & & \\
\hline & $\begin{array}{l}\text { Edukasi dan pemberian alat pengolah sampah plastik } \\
\text { menjadi paving blok }\end{array}$ & & & & \\
\hline
\end{tabular}

\section{Metode Pendekatan}

Hal yang pertama kami lakukan adalah mengidentifikasi masalah yang ada di Desa tersebut, sehingga kami dapat lebih mendalam dan terarah dalam melaksanakan program kerja yang telah kami susun. Adapun program kerja tersebut terdiri dari beberapa tahap :

\section{Tahap observasi}

Pada tahap ini kami mendatangi kepada Desa Cigudeg di Kantor Desa Cigudeg dan mewawancarainya, disamping untuk menjalin silaturahmi dan kekeluargaan, juga untuk mencari informasi mengenai Desa Cigudeg serta mencari permasalahan yang ada didesa tersebut.

\section{Tahap Klasifikasi dan Analisis}

Dalam tahapan ini kami memilah masalah yang telah kami temukan menjadi beberapa kategori, yaitu masalah sangat berat, berat, sedang dan ringan. Kemudian kami menganalisis masalah tersebut dan menentukan manakah masalah yang akan 
menjadi prioritas dan menjadi program kerja kami nantinya.

\section{Tahap Sosialisasi dan Konfirmasi}

Setelah melakukan klasifikasi mengenai masalah yang menjadi program kerja kami, selanjutnya dalam tahap ini kami menyusun program kerja sementara. Setelah itu kami menyampaikan kepada Pihak Pemerintahan Daerah seperti Kepala Desa, RT, RW dan pihak lainnya.

\section{Partisipasi Masyarakat dalam}

\section{Pelaksanaan Program}

1. Mempersiapkan anak-anak agar bersedia untuk mengikuti program yang berbau pendidikan.

2. Mempersiapkan tempat untuk melaksanakan program-program yang telah tersusun.

\section{REALISASI PROGRAM}

\section{Program Bidang Pendidikan}

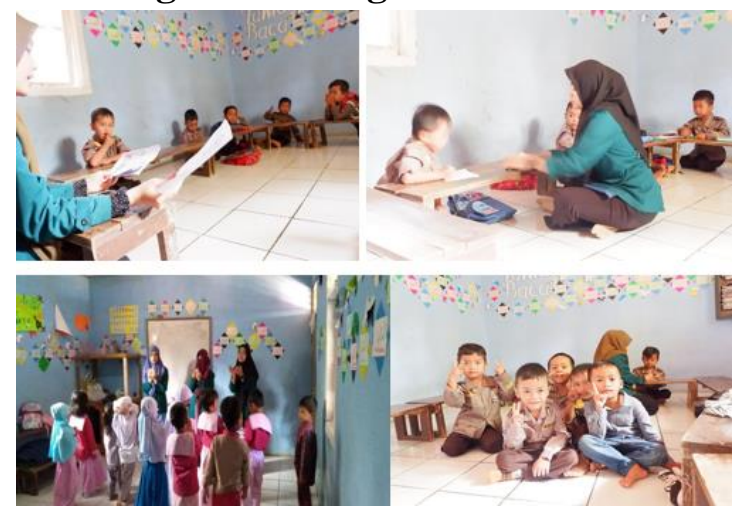

\section{a. Pendidikan Formal}

Pendidikan formal merupakan pendidikan di sekolah yang diperoleh secara teratur, sistematis, dan dengan mengikuti syarat-syarat tertentu yang biasanya tertera secara tertulis maupun tidak tertulis. Program pengajaran formal ini dilaksanakan di dua tempat yaitu SDN Cigudeg 03 dan PAUD Hamidah.

\section{b. Pendidikan Nonformal}

Pendidikan nonformal adalah jalur pendidikan diluar jalur formal. Program pengajaran nonformal yang dilaksanakan
3. Pelaksanaan kegiatan informal seperti pengajian anak-anak, ibu-ibu, bapakbapak, les/bimbel, pembuatan kerajinan dari limbah kayu, daur ulang sampah, dsb.

4. Melakukan monitoring pelaksanaan kegiatan untuk masyarakat.

\section{Langkah Evaluasi}

Evaluasi yang dilakukan dibagi menjadi tiga, yaitu:

a. Evaluasi pertama, dilakukan terkait observasi, analisis, perencanaan dan monitoring kegiatan.

b. Evaluasi kedua, dilakukan setelah program kerja selesai dilaksanakan (dua hari sekali)

c. Evaluasi ketiga, dilaksanakan setelah seluruh kegiatan telah terlaksanakan.

adalah Les/Bimbel Bahasa Inggris bertempatan di Posko 62. Les/Bimbel ini dilakukan agar anak-anak bisa mendapatkan pembelajaran yang lebih menyenangkan.

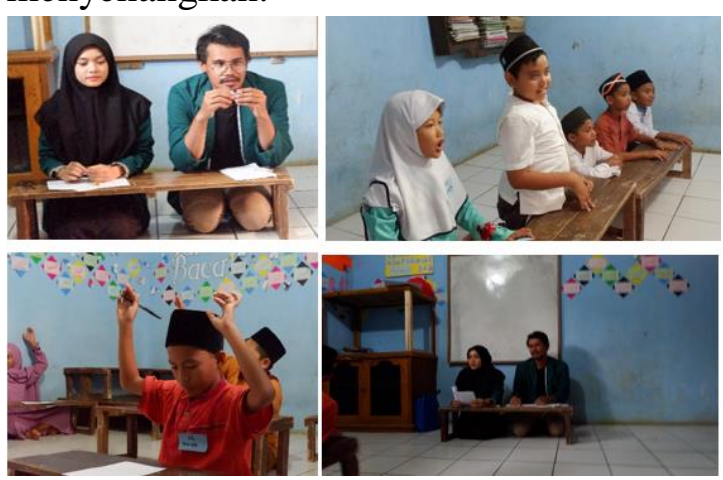

\section{c. Lomba Cerdas Cermat}

Lomba Cerdas cermat ini dilaksanakan bersamaan dengan Lomba Festival anak Sholeh, dalam lomba cerdas cermat terdapat dua perlombaan yaitu, SpellingBee dan Vocabulary. Perlombaan ini diadakan di minggu terakhir, gunanya agar memberikan suatu kesan yang tak ternilai oleh anak didik. 


\section{Program Bidang Ekonomi}
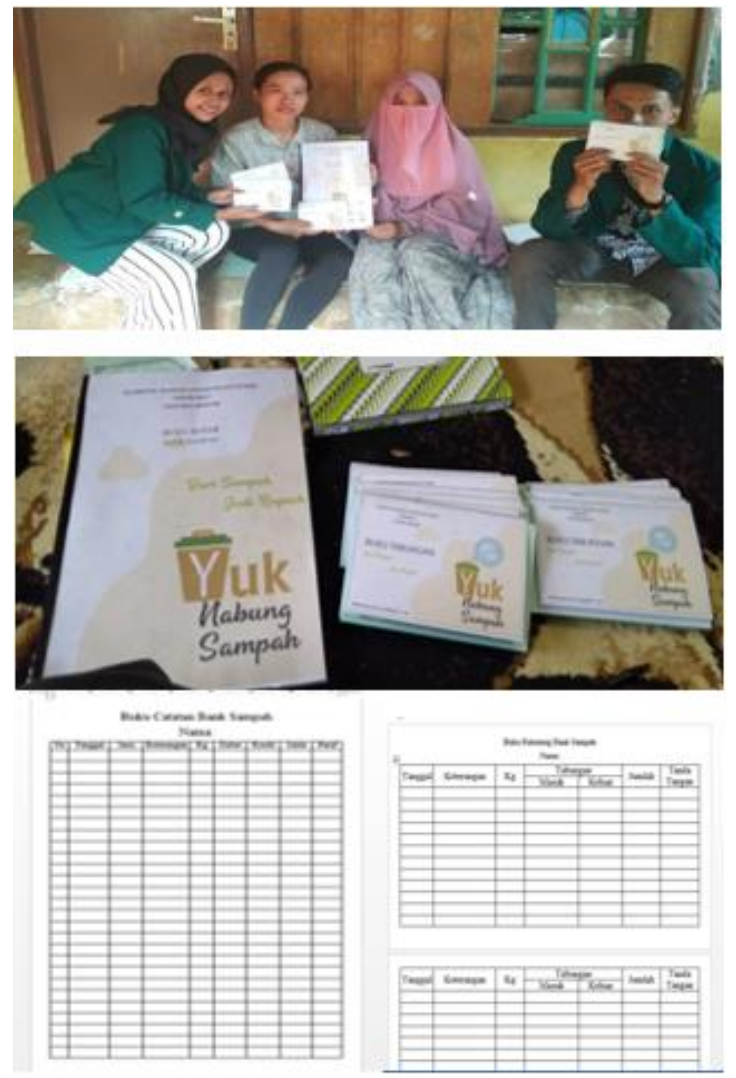

a. Penyuluhan Tabungan Dini

Tabungan dini ditunjukkan untuk anak mulai dari usia 7 tahun hinggal 13 tahun. Tabungan dini diadakan di TPA, tujuan diadakannya tabungan dini adalah untuk memberikan edukasi kepada anak untuk menyisihkan uang saku mereka lalu ditabungkan dan ini juga dapat memberikan kesadaran bagi orang tua untuk membiasakan anak-anak mereka untuk menabung sejak dini

\section{b. Penyuluhan Buku Besar dan Buku Nasabah untuk Bank Sampah}

Dalam penyuluham ini, bertujuan untuk memberikan edukasi bagi anggota Bank sampah tentang buku nasabah dan buku besar yang bertujuan untuk mencatat pemasukan, pengeluaran anggaran warga yang menyetorkan sampahnya kepada bank sampah setiap minggunya, gunanya agar tertata rapih.
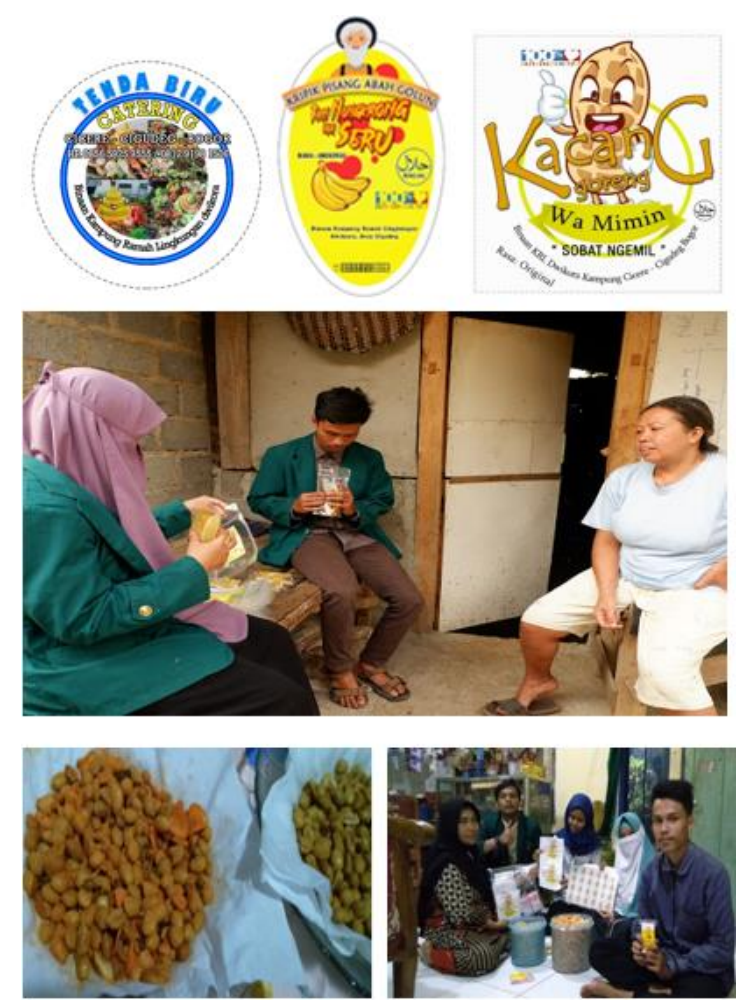

\section{c. Pengembangan Usaha Rumahan}

Pengembangan usaha rumahan ini berfokus pada pengusaha kecil yang telah ada didesa cicere, pengembangan yang kami lakukan antara lain: Menginovasi variant produk, membuatkan kemasan berlabel, dan memasarkan produknya ditempat-tempat wisata.

\section{d. Pengolahan Limbah Kayu}

Didesa Cicere terdapat limbah kayu yang lumayan banyak, kami mengolah limbah tersebut menjadi barang yang lebih bernilai seperti boneka kayu danbo dan mensosialisasikan cara pembuatannya kepada pemuda-pemudi desa agar tak hanya menjadi limbah melainkan menjadi suatu kerajinan di desa tersebut.

\section{Program Bidang Kesehatan}

\section{a. Penyuluhan Prilaku Hidup Bersih dan Sehat di Sekolah (Cuci tangan dan gosok gigi)}

Prilaku hidup bersih dan sehat atau PHBS merupakan salah satu prilaku yang berkaitan dengan upaya seseorang untuk meningkatkan kesehatannya berdasarkan 
kesadaran, sehingga mampu mencegah penyakit. Salah satu sasaran PHBS yaitu anak-anak. Penyuluhan ini diadakan di PAUD Hamidah dan SDN Cigudeg 03, yaitu penyuluhan cuci tangan dan gosok gigi yang baik dan benar.

\section{b. Penyuluhan Stunting}

Stunting atau perawakan pendek (shortness) adalah salah satu keadaan malnutrisi yang berhubungan dengan ketidakcukupan zat gizi saat dalam kandungan yang bersifat kronis. Menurut data Puskesmas Cigudeg, stunting telah terjadi di beberapa kampung di Cigudeg oleh sebab itu kami mengadakan penyuluhan stunting gunanya untuk memberikan edukasi kepada masyarakat bahaya stunting dan memberikan kesadaran kepada Ibu yang sedang mengandung untuk mengkonsumsi cukup gizi untuk mencegah terjadinya stunting, penyuluhan ini dilaksanakan di Masjid Kp.Cicere Rt02/20.

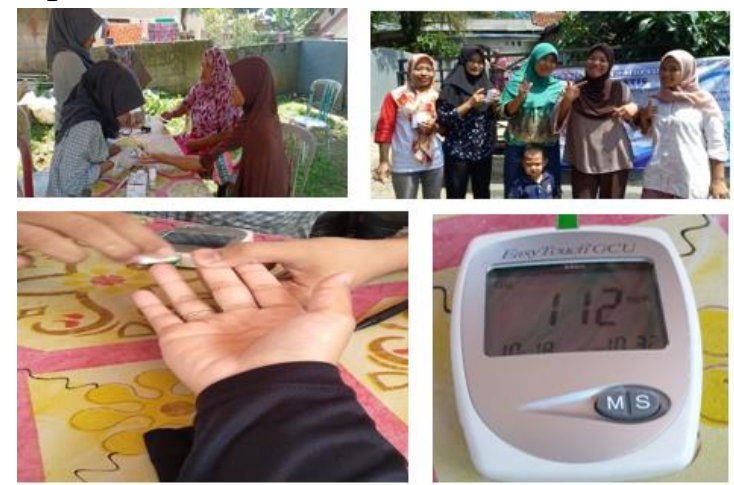

\section{c. Pemberian Cek Kesehatan Gratis}

Pemberian cek kesehatan gratis ini dilakukan di rumah salah satu warga Kp.Cicere RT02/20, yang diberlakukan untuk semua masyarakat RW20 Kp. Cicere Desa Cigudeg, seperti pengecekan Gula darah, berat badan, Asam urat, dan kolestrol.

\section{Program Bidang Agama}

\section{a. Mengajar TPA}

Pengajaran dilakukan di 2 tempat yaitu, Di TPA yayasan Ponpes Mathla'ul Huda pukul 14.00 - 17.00 dan di rumah Bapak RW20 yaitu pukul 18.30 - 20.00.

\section{b. Pengajian rutin warga (ibu- ibu dan bapak-bapak)}

Pengajian rutin Ibu-ibu diadakan pada hari Rabu bertempat di Masjid RT02, Jum'at bertempat di Masjid RT02 dan Minggu bertempat di Yayasan Ponpes Mathla'ul Huda dan pengajian rutin Bapak-Bapak diadakan pada malam senin bertempat di Masjid RT02.

\section{c. Mengajar Agama di SD}

Proses belajar mengajar dilaksanakan di SDN Cigudeg 03, yang dimana dalam kegiatan belajar memgajar dilaksanakan dalam waktu 1 bulan.

\section{d. Festival Anak Soleh}

Festival anak soleh merupakan perlombaan islami yang diadakan khusus untuk anak-anak RW20, festival ini diadakan bertujuan untuk meningkatkan antusiasme anak-anak dalam mengikuti lomba yang bernuansa Islami, dan untuk meningkatkan rasa kepercayaan diri anak berbicara di depan orang banyak seperti Lomba adzan, Hapalan surat pendek, Kaligrafi, dan Pidato.

\section{Program Bidang Teknik}

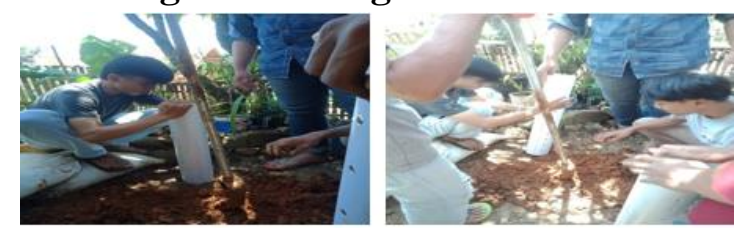

a. Pembuatan Biopori

Biopori merupakan lubang-lubang yang dibuat ditanah dengan diameter 10-30 $\mathrm{cm}$ dan kedalaman $100 \mathrm{~cm}$, Lubang-lubang tersebut kemudian dapat diisi dengan sampah organik untuk menghidupkan mikroorganisme tanah, seperti cacing. Pembuatan biopori ini dilakukan 
dibeberapa rumah warga yang terindikasi banjir atau genangan air saat hujan.

\section{b. Renovasi PAUD}

Renovasi PAUD Hamidah ini dilakukan untuk memperbaiki kerusakankerusakan yang ada di Paud tersebut, seperti internit yang sudah rusak, pagar tembok, dan pengecatan ulang.

\section{c. Pengecatan Jalan dalam rangka KRL}

Pengecatan jalan dilakukan dalam rangka Kampung Ramah lingkungan agar

\section{KESIMPULAN}

Kami menemukan berbagai persoalan yang ada dilingkungan sekitar tempat KKN seperti masalah sampah, kepeduli kesehatan warga sekitar KKN, masalah pembuangan sampah, masalah pendidikan warga kampung cicere, serta kami memberikan solusi terhadap masalah yang ada ditempat wilayah KKN.

Secara umum, program yang kami susun berjalan dengan lancar dan dapat diaplikasikan di masyarakat. Adapun kesimpulan program kerja yang telah di laksanakan :

1. Persoalan yang ada di lingkungan desa Cigudeg kampung Cicere dapat di

\section{SARAN}

Kelompok kami berharap agar setelah KKN, program yang kami telah lakukan di desa Cigudeg kampung Cicere jalana Kp.Cicere terlihat lebih berwarna dan lebih hidup.

\section{d. Edukasi penglolaan sampah plastik}

Edukasi ini menjelaskan cara mengelola sampah menjadi barang bermanfaat seperti paving blok. Selain itu kami juga memberikan alat pengolah sampah plastik menjadi paving blok kepada KRL Dwikora.

selesaikan melalui Program dari 5 bidang yang disusun dapat diterima oleh masyarakat dengan baik.

2. Progam KRL Dwikora dapat berjalan dengan lebih baik dari segi administrasi, green and clean, pengeloaan lingkungan dan sampah.

3. Warga merasa terbantu dan tertolong atas Program KKN UIKA Bogor.

Keberhasilan kami tidak terlepas dari warga setempat, Dosen pembimbing, dan aparatur Daerah yang membantu memberikan kritik dan masukkan, sehingga program kami berjalan dengan baik dan sukses.

masih bisa berjalan dengan baik dan terlaksana. 


\section{DAFTAR PUSTAKA}

Buku Pedoman KKN UIKA

Ikhsan, MZ., Prasetya, EP. (2020). Sosialisasi Pendidikan Stop Aksi Bullying. PKM-P, 4 (1).

Meigy, A.P. (2017). Prilaku Hidup Bersih dan Sehat (PHBS) Anak Panti Asuhan Al-Akbar Pekanbaru. Jurnal Universitan Riau, Vol. 4.2. 1-14.

Nurdin, D.S. (2016). Pendidikan Nonformal, Formal, dan Informal. Pendidikan Guru Sekolah Dasar Universitas Majalengka. Unpublished.

Nurhenu, K. (2011). Teknologi Biopori untuk Mengurangi Banjir dan Tumpukan Sampah Organik. Forum Teknologi Vol. 4.2. 60-68.
Prasetya, E. (2020). 10 Characteristics of SMK Teachers in the Industrial Era 4.0 (Case Study at SMK Bina Profesi Bogor). Edumaspul: Jurnal Pendidikan, 4(1), 50-55. https://doi.org/10.33487/edumaspul.v $\underline{4 \mathrm{i} 1.297}$

Prasetya, E. (2018). Pemberdayaan Masyarakat Tentang Kesehatan, Pendidikan dan Kreatifitas. Abdi Dosen: Jurnal Pengabdian Pada Masyarakat 2 (1), 19-25.

Sutarto, Diana, M., Reni, I. (2018). Stunting, Faktor Resiko dan Pencegahannya. Jurnal Universitas Lampung Poltekkes Kemenkes Tanjungkarang, Bandar Lampung. Vol. 5.1. 540-545. 